\title{
Estratégias discursivas midiáticas: tradición en la contemporaneidad
}

\author{
Carla ReIs Longhi \\ Universidad Paulista \\ carlalonghi@uol.com.br
}

\begin{abstract}
Resumen
Proponemos un análisis de las estrategias discursivas del periódico Folha de S. Paulo sobre un grupo de excluidos, los favelados (moradores de las favelas). La problemática está en el ámbito de la crisis de los paradigmas tradicionales de la cultura, por lo que entendemos que, en una lógica jerárquica y rígida, en sus clasificaciones las representaciones constituidas son más fácilmente justificadas, pero, en un ambiente aparentemente fluido y fragmentado, como indica Canclini, ordenados por la llamada lógica post-masiva, ¿se modifican las estrategias discursivas?
\end{abstract}

Palabras clave- Medio impreso, cultura, estrategias discursivas y representaciones

\section{Midiatic discourse strategies: tradition in contemporary times}

\begin{abstract}
We propose an analysis of the discourse strategies of the newspaper Folha de S. Paulo in respect to a group of excluded persons, the favelados (residents of the slums). The problem is situated in the crisis of the traditional cultural models, understood here in a hierarchic and rigid logic, in its classification the contituted representations are more easily justified, however, in a apparent fluid and fragmented ambient, as Canclini indicates, ordered by a post-massive logic, are the discursive strategies changed?
\end{abstract}

Key words: Print media, culture, discourse strategies and representations

\section{Referencia normalizada:}

Reis Longhi, C. (2013) Estrategias discursivas midiáticas: tradición en la contemporaneidad. Historia y Comunicación Social. Vol. 18. No Especial Diciembre. Págs. 397-409.

Sumario: 1. Introducción. 2.Reflexiones sobre la Cultura. 3.Estrategias Discursivas

\section{Introducción}

Este artículo está fundamentado en los datos de investigación obtenidos en los últimos años de indagación; su eje central ha sido el análisis de la lógica cultural de los medios de comunicación social. Buscamos, en primer lugar, comprender la dinámica cultural y, en segundo lugar, analizar los contenidos vinculados al proceso de construcción de las representaciones mediáticas que surgen en las relaciones sociales. Por lo tanto, hemos establecido algunos recortes de análisis para facilitar la investigación: en primer lugar la delimitación del corpus de investigación, focalizado en el estudio de la impresión; en segundo lugar, se ha elegido un medio de comunicación, el periódico 'Folha de S. Paulo', también se ha establecido un marco de tiempo, que 
comprende el período junio-diciembre de 2009. Observamos la totalidad de las portadas del 'Primero Cuaderno' y la totalidad de los cuadernos 'Cotidiano', incluyendo la cubierta y el contenido interior, tabulando todas reportajes publicadas, independientemente del contenido. A lo largo de este trayecto de investigación, publicamos artículos que tratan de la comprensión de la esfera pública, la concepción del espacio urbano, la concepción de poder, las diferencias en los modos de representación de los diferentes sujetos sociales, entre otras consideraciones.

Para este artículo, se propone una reflexión sobre los procesos de representación social, observando cómo los periódicos, representaciones hegemónicas, construyen las representaciones de los sectores excluidos de la lógica económica. En este sentido, queremos observar, en el ámbito de la cultura, los procesos de alienación de estos sujetos, ya excluidos del ámbito económico.

Esta propuesta considera las profundas transformaciones de los paradigmas culturales, transformados a partir de la década de 1990, entendiendo que los nuevos parámetros anuncian una posibilidad de movilidad no identificada en la práctica. Esta incongruencia entre una proposición conceptual móvil, híbrida, fluida y los procesos de representación de yeso y guiados por parámetros culturales tradicionales son el cuerpo del marco teórico y conceptual de esta investigación.

\section{Reflexiones sobre la cultura}

El primer aspecto hace referencia a los 'sistemas simbólicos' que dan cuerpo a nuestros productos culturales. ¿Qué son los 'sistemas simbólicos'? Según Baite1lo, "símbolos son grandes síntesis sociales, resultantes de elaboración de grandes complexos de imágenes y vivencias de todos los tipos. Por esto las imágenes evocan símbolos y al evocarlos, ritualizan y los actualizan (...)" (Baitello, 2005, p. 17). Es interesante ponderar este aspecto, pues la constitución de símbolos se da en prácticas ritualizadas, que mantienen referencias culturales existentes, alimentándolas y intensificándolas continuamente; Serían las llamadas sociedades sólidas, discutidas por Bauman (2007) o bien presentadas por Baudrillard (2000), en 'O sistema dos Objetos', que demuestra la estructuración simbólica de la sociedad burguesa del siglo XIX a través del análisis de la configuración de los ambientes burgueses mostrados a través tanto del mobiliario y objetos de adorno, como de los materiales utilizados para su confección y distribución, que a su vez garantían la ritualización continúa, imponiendo un gestual (prácticas) que alimentaba ésta lógica simbólica.

El sólido se constituye en una demarcación espacio-temporal clara, estable, viabilizando las prácticas de los ritos que ocurren en éste espacio, en la vivencia del tiempo alimentada por la memoria. 'Así, ponderarnos sobre los sistemas simbólicos nos obliga a caminar en una tesitura compuesta por diferentes líneas que se entrelazan continuamente, el espacio, el tiempo, los ritos y la memoria (ya sea voluntaria, involuntaria, afectiva, individual y/o colectiva). Notamos, entonces, en esta tesitura 
simbólica, la estabilidad de las líneas, sólidas, y, la permanencia de los puntos, los ritos. Si, por un lado, las estructuras sólidas son simbólicas, con denso referencial cultural para alimentar el imaginario y la imaginación, por otro, son fijas, enyesadas, pues según Bourdieu:

“...una vez que fornecen tanto el significado cuanto un consenso en relación al significado a través de la lógica de inclusión/exclusión, se encuentran predispuestas por su propia estructura a llenar funciones simultáneas de inclusión y exclusión, asociación y disociación, integración y distinción.” (Bourdieu, 2011, p. XII).

En éste sentido, ellas se pueden constituir de modo jerárquico y, por esto, podemos entender una polaridad de los sujetos pensantes y creadores de cultura, unos con condiciones de producirla y practicarla y otros con la condición de observador pasivo, qué, en términos conceptuales, expresa la dicotomía de una cultura de élite y una cultura popular. Éste entendimiento de la dicotomía sobre lo culto y lo popular como elemento organizador de la cultura brasileña prevaleció hasta los años 1980, sufriendo rupturas dentro de la Academia a partir de entonces, pero manteniéndose, en parte, como sentido común, a final, los costumbres y prácticas tiene un tiempo propio.

La modernidad líquida (Bauman) desestructuró los sólidos, al rasgar estas líneas, rompiendo tanto la estabilidad del espacio (acortándolo de diferentes modos) cuanto del tiempo (levándolo a la vivencia del inmediato). Un debate abierto, un cambio significativo que aunque no forma parte del objetivo de este artículo, implica una idea singular, un sólido desestructurado, un cambio sustancial que modificó la estructuras base. Sin éstas bases, sus rituales perdieron el sentido. Para Baitello, las imágenes, que evocaban los símbolos, nos encuentran nada más, están vacías "cuando se vacía, traen a la luz y demuestran el vacío de los valores de referencia de una cultura" (Baitello, 2005, p. 15).

Tenemos aquí, un punto de inflexión o de explosión. Pues, por un lado, vemos la afirmación del vacío simbólico presente en Baitello y de otros autores, algunos ya citados como Baudrillard y otros posteriormente discutidos como Muniz Sodré. Por otro lado, si considerarnos Miceli: "Sin embargo, una vez que la cultura solo existe efectivamente sobre la forma de símbolos, de conjuntos de significantes/significados, de donde viene su eficacia propia..." (Bourdieu, 2011, p. XIII), ponderar sobre una cultura es siempre ponderar sobre un modo de constitución de significados, que a su entender son simbólicos. En nuestra opinión no hay antagonismo en esas proposiciones, sin embargo, indican claramente una ruptura de los paradigmas culturales existentes hasta entonces, aspecto que trataremos en éste artículo. Ésta reflexión presupone preguntas como: ¿Qué si constituye en lugar de estos sólidos? ¿Cuáles son los discursos y/o estrategias sobre en éstas nuevas condiciones? ¿Cómo ponderar sobre cultura, hoy, desestructurada de los ejes que a componían?

Empezamos por la última cuestión, para una ruta didáctica del texto. Diferentes teóricos de la cultura (Ortiz, Hall, Martín-Barbero, Miranda, Sodré etc.) vienen ponderando sobre éstas transformaciones, abordándolas sobre enfoques distintos y 
no necesariamente contrapuestos. Canclini (2006), por ejemplo, para desmarcar las mudanzas visualizadas, nombra éste contexto cultural como 'culturas urbanas'. En éstas, el eje se instituye primero por la des-territorialización y por la descomposición, o sea, el desmontaje de los sólidos, con nuevas modalidades de interlocución espacio-tiempo, y, después por la re-territorialización y recomposición, que pasan a ser constituidas en las nuevas bases, no más colectivas, como grandes sistemas, sino, muchas veces individuales, hilvanando influencias espacio-temporales singulares. De algún modo, en ésta proposición, podemos entender que ocurre una liberación de las estructuras enyesadas, anunciando una equiparación del valor de las prácticas culturales que no se presentan de forma jerárquica como acontecía en las estructuras simbólicas anteriores. En éste caso, las ideas de cultura de élite y cultura popular, o sea, la perspectiva dicotómica de la cultura, pierde la fundamentación y se viabilizan las especificidades de cada grupo. La reflexión sobre las dinámicas global-local (ya que las mudanzas prevén nuevas articulaciones espacio-temporales) no es simple, su complejidad ha generado algunos conflictos o debates académicos que aunque importantes no son tópico prioritario de ésta discusión y que por tanto quedarán al margen de este nuestro artículo.

Reanudando nuestros cuestionamiento, partimos del debate sobre la cultura y concordamos con Canclini en cuanto a la fragmentación y fluidez de sus nuevas formas de constitución, al considerar que los ejes guiones de éstas nuevas elaboraciones culturales se pulverizaran, reordenando el papel cumplido por los antiguos aparatos de producción simbólica, instituciones como la familia, escuela, iglesia, etc; concordamos, también, con Baitello cuando discute sobre el vacío de las imágenes, entre otros aspectos, en función de la inmediatez de ésta imagen y de la vivencia, entonces, de un tiempo que es ahora. Cuestionémonos, sin embargo, en cuanto a la amplitud de ésta liberación y sus implicaciones. De ésta forma, reanudando Miceli, podemos ponderar sobre una rearticulación de los modos de producción simbólica, a final "así como no existen puras relaciones de fuerza, también no hay relaciones de sentido que no estaban referidas y determinadas por un sistema de dominación" (Bourdieu, 2001, XIII). ¿Una élite política/cultural efectivamente desmontaría los sólidos de buen grado? Creemos en el límite de manutención de su poder y justamente en los aspectos que impedían su prevalencia. Para Debord, que refleja sobre estas condiciones en el contexto de sus transformaciones, el hecho de si derretir los sólidos no viabilizado una situación indeterminada, al contrario, posibilitó la conformación de la 'Sociedad del espectáculo'. "Pero el espectáculo nada más es que el sentido de la práctica total de un formación económica-social, su empleo de tiempo. Es el momento histórico que nos contiene" (Debord, 1997, p. 16). En ésta cita, destacamos el aspecto que consideramos esencial: la lógica del espectáculo no significa, a penas, la diseminación de un modo de visibilidad, sino, la estructuración de un sistema, una totalidad en la cual nada escapa, pero que no es explicita en sus intencionalidades, ocultando la 'nueva' lógica sistémica y poniendo al individuo y sus supuestas necesidades en el centro de éstas imágenes, que se presentan como estables. 
Ésta dicotomía apariencia/ocultamiento generó lo que Baudrillard denominó simulacro, la producción de una realidad (aparente) en ausencia de la misma (y ocultamiento de su lógica). Ésta dicotomía posibilita, por un lado, su propia sobrevivencia y, por otro lado, la conformación de discursos que se presentan como imágenes estables. Así, los productos culturales se libertaran de una rigidez simbólica, de una rigidez estándar de comportamiento, transformando las costumbres más fluidas. Hay una apariencia de libertad individual y valorización de éste individuo, pero lo que mueve esta dinámica, el sistema capitalista y sus consecuencias para el hombre tanto en la constitución de su sensibilidad, cuanto en su sociabilidad, queda oculto. El vacío de las imágenes y, luego, de las estructuras simbólicas, denota el rasgo de los valores que sedimentaban lo social, estando en cerne de ésta cuestión, la desvinculación social, pues los individuos perdieron la responsabilidad colectiva. En su lugar, tenemos la reflexividad (Giddens, 2002) imponiendo al hombre un continuo revisionismo, con responsabilidad individual.

Ponderemos sobre nuestro objeto de investigación, el análisis de un producto cultural, un periódico. Muchos aspectos sobre la prensa podrían ser destacados y discutidos. Podríamos ponderar sobre las transformaciones de sus sentidos, analizando los significados y modos de constitución de la información periodística, hoy; reflejar sobre las relaciones información-mercado; analizar las especificidades de los distintos segmentos de la prensa; destacar que trata de un medio de lógica masiva, bien como, el hecho de que elegimos un periódico alineado con discursos hegemónicos, constituyendo la llamada 'grande prensa', entre muchos otros aspectos. Para el espacio de éste artículo, delimitamos el debate a la siguiente cuestión: Cómo un periódico de la grande prensa propone la representación de sectores sociales desalineados de la lógica económica y que su simple existencia ya presionaría por la discusión de esta misma lógica. La problemática se insiere en el ámbito de la crisis de los paradigmas tradicionales de la cultura, pues entendemos que, en una lógica jerárquica y rígida en sus clasificaciones, las representaciones constituidas son más fácilmente justificadas, pero, en un ambiente aparentemente fluido y fragmentado, como indicado por Canclini, donde los llamados aparatos culturales conviven con nuevos lugares discursivos, ordenados por la llamada lógica pos-masiva, ¿cambia las estrategias discursivas? Así, proponemos el análisis de las estrategias discursivas del periódico 'Folha de S. Paulo' sobre un grupo de excluidos, los favelados.

\section{Estrategias discursivas}

Empezamos con un esclarecimiento al respecto de la elección del primer recorte analítico. Optamos por observar el modo en que el periódico representa un grupo de excluidos, en el caso, los favelados ${ }^{1}$. El termo favelado es utilizado, a penas, para

1 Éste tema específico fue discutido en el artículo anterior producido por ésta autora. Retomamos aquí la descrición de la tabulación sobre los reportajes periodísticos. 
reproducir la nomenclatura que el periódico usa y no para un posicionamiento político o conceptual. Es, sin embargo, un término enraizado en la cultura brasileña, sus orígenes terminológicos y, luego, de condición de exclusión, remontan el siglo XIX y sobre éste origen, haremos una digresión.

El origen de las Favelas en Brasil remonta al siglo XIX y está asociada a los sujetos considerados, en la época, como las 'clases peligrosas'. Cuando retomamos este período y buscamos las referencias sociales sobre estas clases identificamos, inmediatamente, la referencia a las colmenas, como forma de vivienda y modo de vida predominante. Chalhoub analiza exactamente el proceso de construcción de un discurso sobre las colmenas, en el intuito de exterminarlos, identificándolos tanto con lugares que favorecen el crimen como con la proliferación de enfermedades; de ahí sale la asociación al termo de 'clases peligrosas'. El concepto será construido despacio, des de la apropiación de ideas europeas, transformadas para el contexto brasileño. De ahí la construcción social de la idea de 'clases peligrosas' también se vinculada al trabajo, bien colocado por Chalhoub al recuperar los debates legislativos. Señalamos la presencia de un referente liberal en la estructura de estas ideas; hay una valorización de la acción individual, basada en la competencia laboral, elemento éste que se constituye como el creador social, que justifica la riqueza, la acumulación y la diferencia y que, además, pune la pobreza, creando un arcabuco moral y racional para el control social. Poco a poco, el concepto de 'clases peligrosas' fue ampliado, incorporando el discurso científico de la medicina y las investigaciones sobre criminología. Tratase de un contexto en que el discurso científico se propagaba y adquiría estatus de 'verdad' y, como propone Foucault, la idea de verdad anuncia la exclusión de todo lo que no está contenida en ella. El proyecto de destrucción de las colmenas se asocia directamente a la formación de las favelas.

Teniendo en cuenta el contexto actual, buscamos verificar la forma en que el periódico propone una discusión sobre el binomio cultura - la lógica capitalista. Observemos la siguiente tabla (Tabla I). Se muestra el número de temas relacionados con el grupo social aquí cortado: es decir, los 'okupas', excluidos de las condiciones básicas de vivienda, por lo tanto, excluidos de la totalidad del consumo. Tomamos nota de que el grupo social identificado en este artículo fue objeto de análisis del periódico en el $10 \%$ de sus ediciones, siendo que apenas 3\% fueron reportajes de cubierta del 'Cuaderno Cotidiano':

\begin{tabular}{|l|c|c|c|}
\hline TABLA I & Total de ediciones & $\begin{array}{c}\text { Total de ediciones con } \\
\text { o tema }\end{array}$ & $\begin{array}{c}\text { Total de ediciones con o } \\
\text { tema en capa }\end{array}$ \\
\hline Cuaderno Cotidiano & 183 & 18 & 5 \\
\hline
\end{tabular}

Al considerar sólo los resultados de esta tabla, según Foucault, ocurre un proceso de interdicción inmediata, en esta ocasión, por la rarefacción del sujeto, teniendo en cuenta la visibilidad alcanzada; en este momento no estamos discutiendo la rareza de su autoría, el favelado hablando de sí. Por lo tanto, la visibilidad dada por el periódico a éste grupo y sus especificidades es mínima. Éste aspecto es importante 
cuando reanudamos autores que sostienen que en la esfera pública, se constituye a través de la apariencia; así, qué lo que se ve, es común y reconocido por todos, al paso que, lo que no se hace ver, es como si no existiese. Volvamos a la observación de los reportajes. Proponemos algunos criterios analíticos para la consideración de asuntos que son tema de corte: en primer lugar, se establece una distinción entre reportajes y ediciones que analizan de modo previamente clasificatorio y no clasificatorio a la condición de éste sujeto.

"Desde el principio, la clasificación se define en términos de una operación lógica que consiste en jerarquizar las cosas del mundo sensible en grupos y géneros cuya delimitación presenta un carácter arbitrario. La jerarquía establecida entre las cosas agrupadas en una clase dada tiene mucho más sentido de un orden cuyos cimientos hay que buscar fuera del sistema de clasificación. "(Bourdieu, 2011, XV)

En este supuesto, nos referimos aquí por no clasificación, a la presentación de temas que contribuyen a la construcción de múltiples representaciones de la favela, siendo que, entonces, por clasificación proponemos la referencia a una imagen única y enyesada sobre el tema, es decir, una lugar previamente definido. De las 18 ediciones observadas, estas ediciones pueden contener más de un asunto relacionado con el tema, 3 ediciones trabajaron con materiales que constituyan una visión múltiple sobre el sujeto (un reportaje en cada edición), predominantemente una mirada clasificatoria.

Una de ellas (fig. 1) es edición de 25/10 con sólo un reportaje:

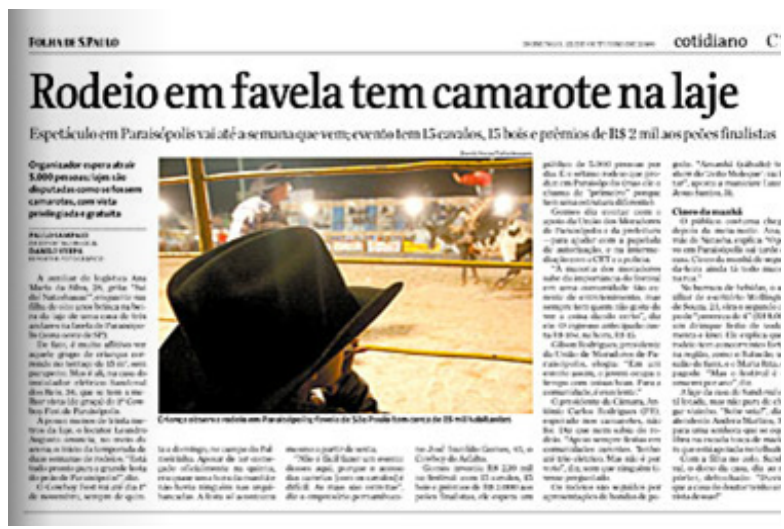

La reportaje (Fig. 1) es emblemático para éste problema: el rodeo se llama ' 1 . Cowboy Fest Paraisópolis' compone influencias de EE.UU., en el título, en referencia a la figura del vaquero, aliado al rodeo regional, en la figura del peatón, esto también transporto desde la zona rural hacía la ciudad, todo organizado por un empresario nordestino, el 'pernambucano' José Gomes Ivanildo y seguido por conciertos de pagode, dificultando la definición de territorios culturales claras, nacional, regional o de clase. En este caso, independientemente de la intención del periódico, termina indicando, según el análisis de Canclini, "una cartografía del espacio social alternativo" (Canclini, 2006, p.314), basado más en las nociones de 'circuito' y 'frontera'. 
Otras tres ediciones que propusieron reportajes que traía una oscilación entre destacar aspectos polisémicas de la favela y reafirmar marcas que caracterizan los problemas estructurales reanudando lugares de clasificación, como en la reportaje que lleva el título: "Favelas reciben encomienda sobre escolta", hay la indicación del consumo, pues sus residentes compran electrodomésticos, como refrigeradores, estufas etc., en una circularidad que da, en los bienes materiales y simbólicos consumidos, pero, los lugares donde viven son violentos y las empresas de entregas organizan escoltas armadas para proteger los patrimonios. Tenemos que reforzar el hecho de que los reportajes que indican un efecto positivo, sobre todo lo hacen para identificar la incorporación de productos/prácticas valoradas por la lógica capitalista. De lo contrario, sólo indican lo que las otras ediciones refuerzan: por un lado la macula y por otro, la criminalización de la pobreza.

En nuestra opinión, la base de estas dos categorías: macula y criminalidad, reanudó las conversaciones sedimentadas durante todo el siglo XX sobre estos temas, estos discursos presentados anteriormente, donde la macula, la idea de ambiente inadecuado y por lo tanto de riesgo y crimen, toma el concepto de las clases peligrosas, la actualización de la misma. En este sentido, vemos categorías de clasificación social en el cuerpo de la propuesta de la representación. Elegimos macula por temor a definir una categoría que indique infelicidad, lacra social, y trayendo en su sentido etimológico, la idea de un 'defecto moral, una mancha en la reputación "(Diccionario Aurélio). Por lo tanto, la elección de la categoría indica la presencia de una ambigüedad que plantea el propio periódico: el sufrimiento con una punta de responsabilidad, responsabilidad ésta sutil. Ya la "Criminalización de la pobreza", al tiempo que denuncia la pobreza, criminaliza, indicando la aparente responsabilidad de estos actores por su propia condición; vemos aquí, lo que Foucault llama de interdicción por tabú, pues la criminalización genera exclusión. Así, el discurso dominante en la mayoría de los sujetos (en 13 ediciones de un total de 18) pone de relieve aspectos clasificatorios, tratados ya sea como maculas sea criminalizándolos. Observamos los reportajes siguientes:

\section{Figuras 2 y 3}
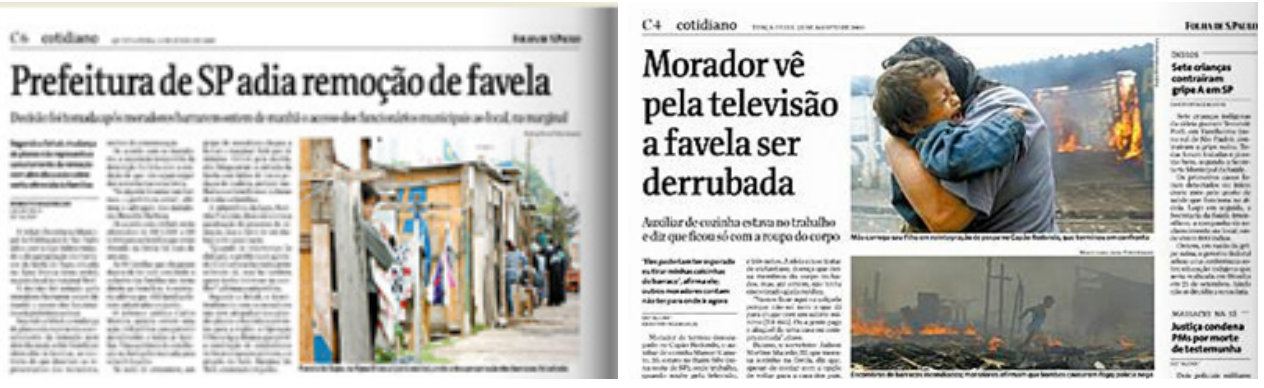

En la categoría macula predominan características descriptivas, mostrando la pobreza (fig. 2); la falta de vivienda de los desalojamientos impuestas por el gobierno; 
el desespero de las madres y las familiares y el sufrimiento de los niños (Fig. 3); los incendios (fig. 3) que culminan en la pérdida de los ínfimos bienes, como destacado en las fotos de arriba. En ambos casos, el dolor indica un sutil sentimiento de culpa, ya que la tierra es la ocupación y el gobierno actúa en la reconstitución de los derechos de los propietarios; En los ejemplos de fuego, hay red ilegal, uso de materiales no adecuados, el exceso de vivienda, etc. En la categoría criminalización también existe la presencia de una dicotomía entre la macula-culpa, creando gradaciones entre los dos aspectos en la aproximación de la responsabilidad visible, que culmina con la penalización explícita. De este modo, las maculas y culpabilidades de éstos excluidos se refieren a la misma cosa: la función social de estos individuos desposeídos dentro de la lógica liberal en el líquido contexto. En este caso, toda la responsabilidad se centra en la reflexividad del individuo discutido por Giddens, que elige la ocupación ilegal y debe acarrear con los riesgos y, además, práctica o apoya la violencia. En ningún ámbito es el conjunto de la función del Estado en la política pública, la reanudación del proceso histórico de la construcción de estos lugares, hecho con el consentimiento de ese Estado o cuestionar las órdenes de desalojo, en cumplimiento del derecho de posesión, o, finalmente, la explotación económica que se lleva a miles de personas que viven en condiciones infrahumanas, en todos los aspectos, el pensamiento liberal imperante, ahora neoliberal. ¿Qué ha cambiado desde el concepto original, construida a finales del siglo XIX en las "clases peligrosas" era su relación con un proyecto de limpieza. En lugar de esto, vemos la construcción de criminalización social puesto en diferentes formas. En la construcción discursiva, el habitante de la favela es hostil de forma gratuita (fig. 4) recibiendo muy mal los visitantes que sólo tratan de ayudarlos. O peor aún, es el papel de los narcos, foco de violencia, que causa miedo y rechazo de la sociedad y reacción de la policía; esta formulación prevalece, con diferentes elaboraciones. Observemos a la figura 5, abajo:

\section{Figuras 4 y 5}

Tonkesprese

Diretores da Bienalde Roterdã vãoafavela e sãohostilizados

Em Faraisópolis, o grupo foil apedocjado per vidlantes do local e parabo por íto coetririo a projebo de reurtanizaplo

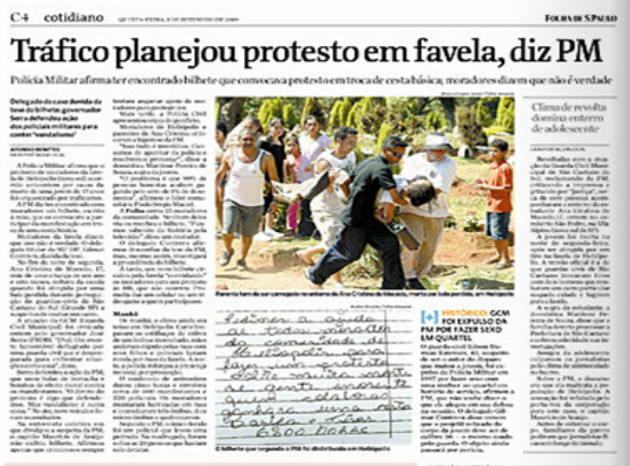

En algunos reportajes hay una estrategia discursiva interesante, pues el periódico presenta un facto, por ejemplo, el reportaje del día 13/07, situación en que una joven $\mathrm{y}$ un bebe fueron baleados por cuenta de un tiroteo entre policías y bandidos. El contenido es recurrente; el periódico trae una crítica directa a la acción de la policía, 
poniendo en sospecha la veracidad de la información, en una lógica textual de aproximación a las víctimas y en defensa a los derechos humanos, finalizando el texto: "aún en febrero, dos periodistas fueron hechos rehenes en la favela, pero acabaron libertos luego después"; A pesar de la crítica a la policía, la favela es puesta en cuestionamiento, independiente de la acción policial, justo en relación a la 'idoneidad' del periodista, o sea, la favela es violenta y peligrosa, qué posibilita la criminalización social y qué enyesa una vez más los papeles sociales definidos a prior. Ésta lógica discursiva que criminaliza y es creación de la culpabilidad, jugando para el morador la responsabilidad de su condición, construida en reportajes con diferentes estrategias: destaque puesto en los titulares como en las figuras 4 y 5 ya presentadas, caracterizándolos como hostiles, crimonosos y violentos; En la figura $6(13 / 10)$ que destaca el facto de la invasión, ocupación ilegal y en la figura 7 (14/10), que a pesar de no apuntar directamente hacía algún acto de culpa, indicando la construcción del texto verbal, en el retraso en la entrega de viviendas, qué remete a los derechos de los moradores de la favela destaca, en su imagen, un ambiente de caos asustador, pareciendo casi animales; en éste caso, la imagen traspasa miedo.

\section{Figuras 6 y 7}

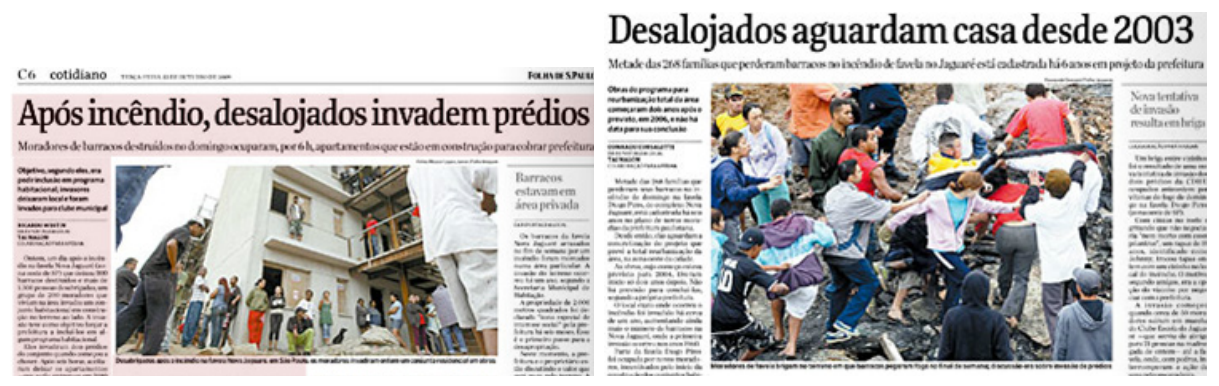

Podemos observar, entonces, que las representaciones de excluidos constituyen sedimentado en dos bases: la primera es el mantenimiento de una mirada cultural tradicional, luego, jerarquizada y clasificatorio, a pesar de los continuos cambios procesados en su eje; el segundo es la intensificación del discurso de la modernidad que anuncia la diversidad, la fluidez vista como libertad ocultando, entonces, el mantenimiento de una perspectiva cultural jerárquica, dicotómica que no reconoce los diferentes y luego no tiene la intención de tratar con él; para que toda proposición que es una jerárquica desigual, autoritaria y por lo tanto, violenta. Estos son los aspectos que están ocultos. En primer lugar: la violencia y el autoritarismo del sistema, ocultando el origen de las diferencias socio-económicas y el hecho de que esta diferencia es un elemento constitutivo del propio sistema capitalista, construyendo como estrategia discursiva la idea de que la persona es responsable de su propia condición. En segundo lugar: la violencia y el autoritarismo del medio, en el caso el periódico, que articula las estrategias discursivas de la zona de este tipo, sosteniéndolo. Veamos la composición abajo,(fig.8), que articula el discurso del material periodístico con el de la publicidad: 


\section{Figura 8}

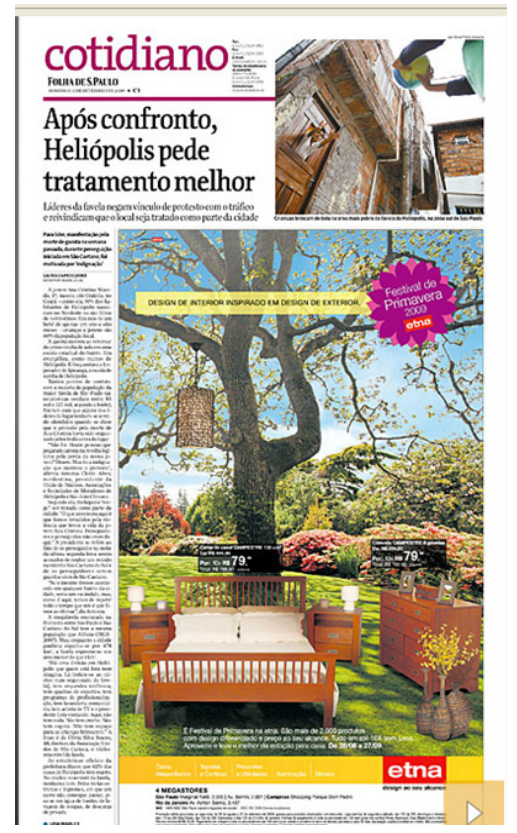

El reportaje es acerca del barrio de Heliópolis, 06/09, favela que días antes (02/09) se había enfrentado con la policía debido a la muerte de una joven por una bala perdida. "Después de la confrontación, Heliópolis pide un mejor tratamiento" es el título del artículo. Aquí vemos claramente las estrategias y tácticas en juego. La portada de este número articula una historia cuyo título hace hincapié en el deseo de estatus social y una pieza de publicidad que expone este deseo con claridad, es un complejo de viviendas. Es interesante darse cuenta, en este caso, la clara conexión temática, la vivienda, basada en un sistema de valores que se organiza en torno a la idea de "calidad de vida", ofertas de publicidad que, en contraste con la situación de los excluidos, ya culpado por su condición. En cierto modo se trata de dos productos diferentes dentro del diseño de la cubierta, pero el diálogo que teje demuestra, en primer lugar, la estrategia de mercado que rige las perspectivas sociales, lo que indica que dentro de la lógica capitalista, un lugar circunscrito, la felicidad se hace con el dinero y la capacidad de consumir estos productos materiales y simbólicos incluyendo esa visión en la opinión de los sujetos sociales, los objetos de deseo y definición de "un dominio de los lugares por la vista".

Esta lógica, hecha con contenido sólido de los reportajes a respecto de este grupo social, apoya la individualización y la responsabilidad reflexiva, delegando la culpa del fracaso a la persona. En segundo lugar, demuestra las estrategias de la prensa, que demarca su relación con el mercado, qué en sí mismo ya definiría la línea editorial de la misma, y, confirma los papeles sociales de las diferentes posiciones de los sujetos; en cuyo caso, el lugar de los favelados, que no es el consumidor y no consume el 
producto anunciado, está presente en la fotografía en la parte superior derecha de la página, es decir, el producto de consumo éste que fomenta el miedo, miedo de ser excluidos socialmente, miedo de ser descartado por la ineficiencia individual, como Bauman ya ha discutido. Este proceso constituye la estructura de la representación que, en si misma, nunca es natural, ya que, como se indica en Chartier, cada representación indica una lógica de poder.

Así, en el interior de un debate cultural que propone un paradigma multifacético, fluido y fragmentado, abierto a influencias que circulan en diferentes medios, espacios y tiempos, el periódico construye un discurso periodístico pautado por el paradigma tradicional de la cultura, calcado en la clasificación social. Una vez más, como plantea Milton Santos, la lógica de la globalización propone un discurso de fábula y una práctica de perversidad.

\section{Bibliografía}

Libro, un autor

BAITELLO JR, Norval. (2005) A era da Iconofagia. Ed. Hacker, São Paulo.

BAUDRILLARD, Jean. (1991) Simulacros e Simulação. Relógio D’Agua, Lisboa.

BAUDRILLARD, Jean. (2000) O Sistema dos Objetos, Perspectiva, São Paulo.

BAUMAN, Z. (2004) Vida líquida, Jorge Zahar, Rio de Janeiro.

CANCLINI, Nestor G. ( 2006) Culturas Hibridas, Edusp, São Paulo , 4. ed.

CERTEAU, Michel de. (1994) A Invenção do Cotidiano, Vozes, São Paulo, tomo I.

CHARTIER, Roger. (1990) A História Cultural-entre práticas e representações, Difel, Lisboa.

DEBORD, (1997) A Sociedade do Espetáculo, Contraponto, Rio de Janeiro.

FOUCAULT, Michel.(1988) Microfisica do poder, Edições Graal, Rio de Janeiro, $7^{\text {a }}$. Ed.

(2010) A Ordem do Discurso, Edições Loyola, São Paulo, $20^{\mathrm{a}}$. Ed.

GIDDENS, Anthony. (1991) As Consequências da Modernidade, UNESP, São Paulo.

HABERMAS, Jurgen. (1984) Mudança Estrutural da Esfera Pública, Tempo Universitário, Rio de Janeiro.

HAROCHE, Claudine. (2008) A Condição Sensível, Contra Capa, Rio de Janeiro.

MIRANDA, José A. Bragança.(2002) Teoria da Cultura, Edições Século XXI, Lisboa.

SANTOS, Milton. (2006) Por uma Outra Globalização, Record, Rio de Janeiro.

SODRÉ, Muniz. (2011) Antropológica do Espelho, Vozes, Petrópolis. (2006) As Estratégias Sensiveis, Vozes, Petrópolis.

Libro, varios autores 
ARANTES, Antonio. (1984) Produzindo o Passado: estratégias de construção do patrimônio Cultural, Brasiliense, São Paulo.

BAITELLO, Norval. (org) (2005) Os Meios da Incomunicação, Annablume, São Paulo.

Revistas científico-profesionales de primer y segundo nivel

CANCLINI, N. G. (2002) Cidades e Cidadãos imaginados pelos meios de Comunicação IN Opinião Pública, Campinas, vol. VIII, n.1.

CHARTIER, Roger. (1991) O Mundo como Representação IN Estudos Avançados $\mathrm{n}$. 11, São Paulo.

Diarios

JORNAL FOLHA DE S. PAULO- CADERNO COTIDIANO- JUNHO DE 2009 NOVEMBRO DE 2009.

\section{La autora}

Carla Reis Longhi es Doctora en Historia Social por la USP / SP y realiza su Pos-Doctorado en Comunicaciones en la Facultad de Ciencias de la Información de la Universidad Complutense de Madrid. Es profesora del Programa de Posgrado en Comunicación (PPGCOM) en la Universidad Paulista. Actualmente es Coordinadora del curso de Historia en la PUC / SP. Realiza investigaciones en el Grupo "Medios, cultura y política: Identidades, representaciones y configuraciones de público y privado en el discurso de los medios", registradas con CNPq. 